\title{
Exploration of Inappropriateness of E-C Trademark Translations
}

\author{
HE Lin-han, MA Shu-xia \\ University of Shanghai for Science and Technology, Shanghai, China
}

\begin{abstract}
Based upon an exploration of the versions of trademarks mainly from English into Chinese, this thesis illustrates some typical examples of inappropriateness for trademark translations and analyzes some factors that would influence the way a trademark is rendered. In addition, certain tactics for improvement are recommended.
\end{abstract}

Keywords: translation of trademark, inappropriateness, tactics

\section{Introduction}

With China's reform and opening-up policy, an increasing number of foreign products have entered China markets. All these products, however, may face a common problem, i.e., how to properly translate their trademarks into Chinese? Trademark translation is not an easy task as imagined by common people. It involves the proper combination of language, politics, culture, geography, customs, consumer psychology, and even law requirements. Practices have shown that an appropriate trademark translation is of vital importance for a foreign brand to survive and thrive in the fierce competitive market in China. However, even some well-known foreign companies make mistakes while translating their trademarks into Chinese.

\section{Inappropriateness in Trademark Translation}

On March 22, 2017, two years after entering the China market, Airbnb, an US online marketplace and hospitality service, named its company in Chinese as: 爱彼迎. “These three characters (爱、彼、迎), if individually, can be seen everywhere in China, but when combined, they have an entirely new meaning: 让爱彼 此相迎 (let love embrace each other)”, said by Brian Chesky, CEO of Airbnb, at a press conference. Soon “爱 彼迎” was teased as a tongue twister. It turns out that “爱彼迎” sounds very much like a famous Cantonese song named “爱拼才会赢 (fight your fortune)” when you say it fast. Based on our observations, such unexpected mistakes often occur in trademark translations. In this article, the author will analyze three main aspects which may cause some inappropriateness or misinterpretation in the course of the trademark translations.

\section{Linguistic Ambiguity}

For ages, Chinese people have attached great importance to how to name a person. Confucius (551-479BC), one of the most famous philosophers in ancient China, once put it, "if one's name is not correct, his words will

HE Lin-han, N/A, master candidate, College of Foreign Languages, University of Shanghai for Science and Technology, Shanghai, China.

MA Shu-xia, associate professor, M.A., College of Foreign Languages, University of Shanghai for Science and Technology, Shanghai, China. 
make no sense". Chinese is considered as one of the most complicated languages in the world. Modern Chinese Dictionary contains more than 13,000 Chinese characters and 82 percent of these characters have homophonic phenomena, which means that the slightest neglect would cause a great difference in understanding (JIANG, 2014). For example, the Chinese character “忠” means “loyalty”, so parents name their child “宋忠”, hoping that their child is loyal to them and his country as well. But the pronunciation of this name is exactly the same as another Chinese phrase “送终”, which means “attend upon a dying parent or other senior member of one's family. Such inappropriateness is also likely to be found in trademark translation, e.g., Warsteiner, the largest privately owned brewery in Germany, ranks fifth among Germany's best-selling breweries. Warsteiner beer's sales in China, however, were so marginal that it even intended to withdraw from China's market. But Warsteiner, after a survey, found the problem of its declining sale was its trademark in Chinese, translated as “沃斯乐”, sounding very similar to “我死了”, which means "I am dead" in English, so it is not strange that Warsteiner failed to make good sales in China.

\section{Deviation From Consumer Psychology}

One of the goals of good trademark translations is to help the company to promote its products. Therefore, trademark translation should be based on consumer psychology and take into consideration consumers' different backgrounds, purposes, and requirements (LUO, 2010; CHEN, 2004). Nutrilia, a world-leading European dairy firm, is famous for its powdered infant formula, one of which is Nutrilon. When Nutrilon was first introduced into China in 2013, its Chinese name was “牛栏”. Though the sound of “牛栏” was similar to that of "Nutrilon”, its sales in China kept low until its brand name was retranslated into good-sounding Chinese “诺优能”. Compared with “牛栏” which means “cattle pen” in English, “诺优能” may cause Chinese customers to associate it with the concept of "promise to nurture your children with high quality". Since then, Nutrilon sales have gone up robustly.

Mercedes-Benz does not become a household trademark in China until its German name is properly localized. The reason why Mercedes-Benz chooses “奔驰” instead of “本茨”, “平治”, or “宾士” as its Chinese name is that a trademark must meet the principles of consumer psychology if it needs to survive and thrive. The Chinese characters such as “速”, “奔”, “腾”, and “驰” indicate high speed. Speed means significantly to a car owner and that is why “奔驰” is so popular that it ranks China's top three luxurious best-selling cars.

\section{Cultural Orientation}

If a foreign trademark wants to enter the international market successfully, it should take into account the traditional culture, values, race, and religion of the target country (MA, 2007). In 1977, Yves Saint Laurent, a French luxury fashion house, marketed a new fragrance named "opium". Soon "opium" is the best seller among the world except for China. It turns out that "opium" reminds the Chinese people of the Opium War in 1840, thus being banned to sell in China according to PRC (People's Republic of China) Trademark Law.

When it comes to the cultural orientation, dragons can trigger different imaginations. The two most well-known symbolic dragons under different cultures are the European dragons and the Chinese dragons. European dragons are usually depicted as malevolent under Christianity, while Chinese dragons symbolize potent and auspicious power and good luck. Among China's top 500 brands in 2015 selected by China Brand Value Research Institute, 11 of them contain the character “龙” (see Table 1). 
Table 1

Trademarks Containing “龙”

\begin{tabular}{|l|l|}
\hline 龙湖 & Longfor \\
\hline 金龙客车 & King Long \\
\hline 红星美凯龙 & Macalline \\
\hline 红金龙 & Golden Dragon \\
\hline 堡狮龙 & Bossini \\
\hline 威龙 & Grand Dragon \\
\hline
\end{tabular}

Dragon is considered evil in the Western world, so the above English names like "Golden Dragon" and "Grand Dragon" might not be appropriate under the Western culture. However, since dragon is the symbol of power in China, quite a few foreign trademarks are associated with the character “龙” in their respective Chinese translations (see Table 2).

Table 2

Trademarks Translated With the Chinese Character “龙”

\begin{tabular}{|l|l|}
\hline Mont Blanc & 万宝龙 \\
\hline Citron & 雪铁龙 \\
\hline Metro AG & 麦德龙 \\
\hline Bugatti Veyron & 布加迪威龙 \\
\hline Bolon & 暴龙 \\
\hline
\end{tabular}

\section{Tactics for Improvement in Trademark Translation}

A trademark is a recognizable sign which is purported to differentiate products or services from others. The essential function of a trademark is to manifestly identify its distinctive commercial source or origin of products or services. Therefore, when translating a trademark, it is essential to retain its original meaning.

\section{Transliteration}

Transliteration is the most common method of trademark translation. Generally speaking, transliteration can be applied when a foreign trademark does not have a complete meaning to the Chinese people. Since Chinese people prefer using words that symbolize happiness, luck, and fortune to name a product, such as “喜”, “宝”, “康”, “发”, etc., more attention should be paid to such aesthetic taste. For example, consonants like "b", "f”, and “l” would be better translated as “宝”, “富”, “力”, while syllables like “si”, “le”, and “fo:y” as “喜”, “乐”, “芳”. Some impressive versions of trademarks can be seen in Table 3.

Table 3

Examples for Pursuing Aesthetic Taste

\begin{tabular}{|l|l|}
\hline Marlboro & 万宝路 \\
\hline Dunhill & 登喜路 \\
\hline Lego & 乐高 \\
\hline Carrefour & 家乐福 \\
\hline
\end{tabular}

However, not all trademarks are suited for transliteration. A relatively longer trademark, like Yves Saint Laurent, is hard to remember if transliterated as “伊夫·圣·洛朗”, whereas a short spelling of “圣罗兰” would be much better and easier to remember. 


\section{Free Translation}

Free translation can be applied when a trademark itself is completely meaningful and acceptable to Chinese people. Nestlé, a Swiss transnational food and drink company named after its founder Henri Nestlé, is a perfect example. Since the French word "Nestlé" and the English word "Nest" have the same root with the famous Nestlé logo of a mother bird feeding its nestlings, no other names could be better than “雀巢”, which not only expresses the literal meaning of "Nestlé" (meaningful), but also well displays a mother's love (acceptable).

However, adjustments should be made in case some trademarks might be meaningful but not acceptable. For example, if Seven-up is literally translated as “七上”, the vast majority of Chinese will associate it with a Chinese idiom “七上八下”, which means you have butterflies in your stomach. In this case, the adjustment is necessary. As mentioned above, Chinese people's preference to the auspicious names as “喜”, “宝”, “康”, “发”, etc., so “七 喜” could be more welcoming and acceptable at large in China.

\section{Combination of Free Translation and Transliteration}

This method gives consideration both to the sound and meaning of a trademark. Coca Cola, a world-famous carbonated soft drink, refers to two of its original ingredients, which are cola nuts (a source of caffeine) and coca leaves. Coca Cola first landed in China in 1927, but its sales were very unsatisfactory in the first year. Therefore, the Coca Cola Company did enormous amount of research and found three reasons. Firstly, color. The black-brown Coca Cola looks very much like traditional Chinese medicine. Secondly, taste. Since Coca Cola is a carbonated drink, there are many bubbles bursting when people drink it. Therefore, rumor had it that Coca Cola would explode out of one's stomach. The first two reasons, in balance, are attributed to eating habits, which means people can get used to it with the passage of time. What really matters is the third reason: its Chinese name “蝌蝌啃蜡”. Though “蝌蝌啃蜡” remains the sound of Coca Cola (Transliteration), it makes the Chinese people associate it with a swarm of tadpoles gnawing candles in the water. In that regard, the company took consumption preference into consideration and renamed it “可口可乐”. Since “可口” means “tasty” and “乐” means “joyful”, since then on, Coca Cola has gradually become one of top beverage brands in China.

Another good example is the fragrance named Poison. For the Westerners, the fragrances of the Poison take new directions with daring provocation. They are fragrances created to feel fresh and relaxed. It is also, sometimes, associated with femininity but with confidence. Since Poison has a meaning in Chinese which means “毒药”, it might not be acceptable to the Chinese people who, for a long time, have been influenced by Confucianism. Under such circumstances, Poison is translated as “百爱神”, which tactfully avoids the unfavorable meaning of Poison.

\section{Conclusion}

To sum up, as far as foreign businesses are concerned, a well-suited E-C translation of trademark is most crucial for their successful entrance to China market. Just as the previous analysis proved that the inappropriateness of trademark translations does make a great difference between a brand's life and its survival. Hence, some basic concepts must be kept in mind in rendering a trademark from English into Chinese. Firstly, accuracy. Linguistic ambiguity causes negative effect on the target language readers. Secondly, a study on consumer psychology. It matters whether the products meet the customers' demand. Thirdly, cultural orientation. Owing to different peoples with different beliefs, social values, and religions, the translated names of trademarks tend to have a great impact on the customers' preference for the purchase. 


\section{References}

CHEN, F. Y. (2004). On functionalist theory in brand name translation in the light of consumer psychology. Sichuan: Sichuan Normal University.

JIANG, M. (2014). Translation of trademarks under the background of intercultural communication. Journal of Shanghai University of International Business and Economics, 6, 67-73.

LUO, Y. (2010). On advertisement and its effect on consumer psychology. Hubei: Hubei Finance and Taxation College.

MA, Y. L. (2007). Studies on brand name translation from the perspective of cultural difference. Shanghai: Shanghai International Studies University.

WU, F. J. (2004). A contrastive study on ambiguity in Chinese and English. Wuhan: Huazhong University of Science and Technology. 